\title{
Spontaneous oxidation of bis(heteroaryl)methanes and bis(heteroaryl)carbinols to ketones
}

\author{
Luciano Forlani,* Carla Boga, Erminia Del Vecchio, and Michela Padovani \\ Dipartimento di Chimica Organica 'A. Mangini', Viale Risorgimento, 4, 40136-Bologna- Italia \\ E-mail: forlani@ms.fci.unibo.it
}

Dedicated to Prof. Paolo Edgardo Todesco, on his $70^{\text {th }}$ birthday

(received 10 Sep 03; accepted 08 Dec 03; published on the web 02 Jan 04)

\begin{abstract}
Oxidation reactions of bis(heteroaryl)methanes to the corresponding ketones were investigated in the absence of usual oxidation reagents and catalysts. There are strong indications that the reaction pathway involves radical species. The spontaneous oxidation of bis(heteroaryl)carbinols was also investigated by kinetic measures. Strong base catalysis, together with relevant hydrogen/deuteron isotopic effect, were observed. Both reaction pathways, from methane derivatives and from carbinols derivatives, involve the presence of a tautomeric equilibrium of the considered heterocycles.
\end{abstract}

Keywords: Oxidation, kinetics, tautomerism heterocycles

\section{Introduction}

The oxidation reaction of hydrocarbons by molecular oxygen is usually carried out by metal catalysis. ${ }^{1,2}$ Aerobic auto-oxidation of hydrocarbons was reported to be enhanced by the presence of non-ionic and cationic surfactants. ${ }^{3}$ Some hydrocarbons are oxidised in the presence of $N$ hydroxyphthalimide and metals or quaternary ammonium bromide. ${ }^{4}$ Potassium superoxide was reported to initiate autoxidations of some arylmethanes. ${ }^{5}$

Spontaneous oxidation of aryl methanes or of the corresponding carbinols, by atmospheric oxygen, in the absence of common oxidising reagents, is an unusual reaction.

Auto-oxidation of weakly acidic carbon atoms is known to occur in the presence of potassium $t$-butoxide in apolar solvents (benzene) or in poly(ethylene glycols). ${ }^{6}$ Under these experimental conditions, fluorene and diphenylmethane are oxidised to fluorenone and benzophenone, respectively. On the contrary, the oxidation of bis(heteroaryl)methanes or bis(heteroaryl)carbinols such as bis(2-benzothiazolyl)methane ${ }^{7}$ (1A) or of bis(2benzothiazolyl)carbinol (2A) to bis(2-benzothiazolyl)ketone (3A) (see Scheme 1) is a 
spontaneous reaction $^{8}$ in working up the solutions of $\mathbf{1 A}$ and $2 \mathbf{A}$ and it may be an undesired side reaction in all studies of $\mathbf{1 A}$ and $\mathbf{2 A}$ and of related compounds. For example, the studies of the $\mathrm{NH} / \mathrm{CH}$ tautomerism ${ }^{8,9}$ on $\mathbf{1 A}$ (and on the related compounds) are complicated by the formation of carbinols 2 or ketones 3 .

$$
\begin{array}{ccc}
\mathrm{Ar}_{2} \mathrm{CXH} & \mathrm{Ar}_{2} \mathrm{CO} \\
\mathrm{X}=\mathrm{H}, \mathbf{1} ; \quad \mathrm{X}=\mathrm{OH}, \mathbf{2} & \mathbf{3}
\end{array}
$$

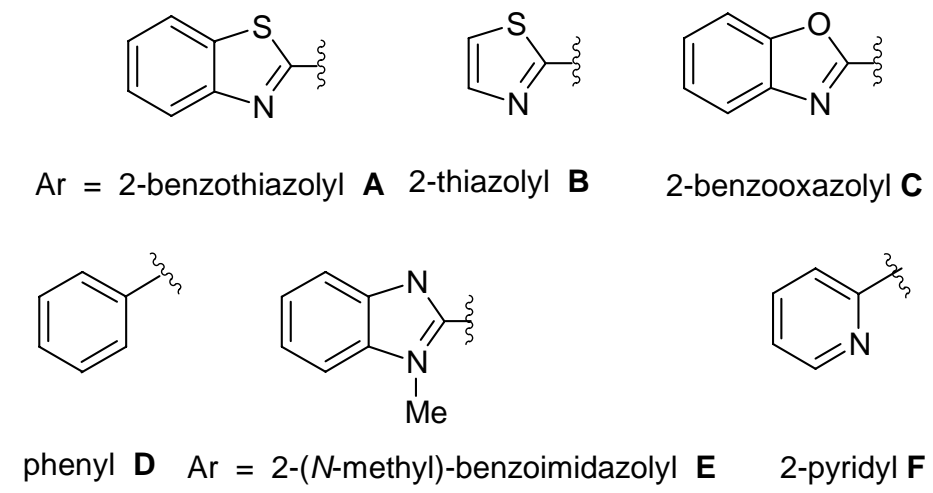

\section{Scheme 1}

Previously, ${ }^{10}$ we reported the oxidation of $\mathbf{1 A}$ to 2,2-tetrakis(2-benzothiazolyl)ethane (4) by using a general oxidising reagent. Solutions of $\mathbf{4}$ are unstable and spontaneously give $\mathbf{5}$, as illustrated in Scheme 2

$$
\begin{aligned}
& 1 \mathrm{~A} \stackrel{\mathrm{Ox}}{\longrightarrow}(\mathrm{BTZ})_{2} \mathrm{CH}-\mathrm{CH}(\mathrm{BTZ})_{2} \longrightarrow(\mathrm{BTZ})_{2} \mathrm{C}=\mathrm{C}(\mathrm{BTZ})_{2} \\
& \mathrm{BTZ}=\text { 2-benzothiazolyl }
\end{aligned}
$$

\section{Scheme 2}

\section{Results}

\section{Oxidation of bis(heteroaryl)methanes (1) to bis(heteroaryl)ketones (3)}

Firstly, we investigated the reaction of compound 1A (and of some other bis-heteroaryl methanes) by changing some experimental conditions. The main results are summarised in Table 1. 
In DMSO, the oxidation of $\mathbf{1 A}$ to ketone 3A occurs in the presence of the oxygen. Under our experimental conditions, bases such as tertiary amines catalyse the oxidation reaction of Scheme 1: the presence of base is important as well as the presence of an oxidising species, which may be the dimethylsulfoxide. The presence of water smoothly enhances the reactivity.

The reactions carried out in the presence of an acid catalyst $\left(\mathrm{CH}_{3} \mathrm{SO}_{3} \mathrm{H}\right)$ produces $3 \mathrm{~A}$ in very low yields (less than 10\%) in 3 days, while addition of an excess of $\mathrm{H}_{2} \mathrm{O}_{2}$ (see experimental section) quickly afforded $\mathbf{3 A}$.

Under the same experimental condition of reaction of 1A, diphenyl methane (1D) is not converted into ketone 3D, bis(2-benzoxazolyl)methane (1C) instead, is converted into the correspondent ketone $3 \mathrm{C}$ by a rate considerably slower than that of $\mathbf{1 A}$. Compounds $\mathbf{1 C}$ and $\mathbf{1 F}$ are reported to produce corresponding ketones $\mathbf{3 C}$ and $\mathbf{3 F}$ by oxidation with $\mathrm{Cr}_{2} \mathrm{O}_{6} \cdot{ }^{11,12}$ Addition of water to the reaction mixture produces moderate increase of the reactivity.

Table 1. Oxidation reactions of bis(2-benzothiazolyl)methane (1A), (unless otherwise indicated) [0.1 mmol in $2 \mathrm{~mL}$ of solvent] to bis(2-benzothiazolyl) ketone (3A)

\begin{tabular}{lllll}
\hline Entry & \multicolumn{1}{c}{ Solvent } & \multicolumn{1}{c}{$\begin{array}{c}\text { Base }^{\mathrm{a}} \\
\text { (experimental conditions) }\end{array}$} & $\begin{array}{l}\text { Reaction } \\
\text { time }\end{array}$ & \multicolumn{1}{c}{ Yield $^{\mathrm{b}}$} \\
\hline 1 & DMSO or $\mathrm{CH}_{3} \mathrm{CN}$ & $\mathrm{Et}_{3} \mathrm{~N}$ & 12 & 100 \\
2 & $\mathrm{DMSO}$ or $\mathrm{CH}_{3} \mathrm{CN}$ & $\mathrm{DABCO}^{\mathrm{d}}$ & 8 & 98 \\
3 & $\mathrm{CH}_{3} \mathrm{OH} / \mathrm{H}_{2} \mathrm{O}$ & $\mathrm{KOH}$ & 12 & 50 \\
4 & $\mathrm{DMSO}$ & ---- & 36 & 52 \\
5 & $\mathrm{DMSO}$ or $\mathrm{CH}_{3} \mathrm{CN}$ & $----\left(\mathrm{N}_{2}\right)$ & 36 & 0 \\
6 & $\mathrm{DMSO}$ & $\mathrm{Et}_{3} \mathrm{~N}\left(\mathrm{TEMPO}^{\mathrm{e}}\right)$ & 24 & 0 \\
7 & $\mathrm{DMSO}$ & $\mathrm{Et}_{3} \mathrm{~N}(\mathrm{in}$ the dark) & 12 & 95 \\
8 & $\mathrm{DMSO}$ & $\mathrm{Et}_{3} \mathrm{~N}\left(\mathrm{H}_{2} \mathrm{O}\right)$ & 8 & 100 \\
9 & $\mathrm{THF}$ & $\mathrm{Et}_{3} \mathrm{~N}$ & 24 & 80 \\
10 & $\mathrm{THF}$ & $\mathrm{Et}_{3} \mathrm{~N}\left(\mathrm{~N}_{2}\right)$ & 36 & 0 \\
11 & $\mathrm{THF}$ & $\mathrm{TEMPO}^{\mathrm{e}}$ & 36 & 0 \\
$12^{\mathrm{f}}$ & $\mathrm{DMSO}$ & $\mathrm{Et}_{3} \mathrm{~N}$ & 36 & 25 \\
$13^{\mathrm{g}}$ & $\mathrm{DMSO}$ & $\mathrm{Et}_{3} \mathrm{~N}$ & 36 & 0 \\
\hline
\end{tabular}

${ }^{\mathrm{a}}$ [base $]=0.05 \mathrm{mmol}$, initially added. Under aerobic conditions, unless otherwise indicated. ${ }^{\mathrm{b}}$ For reactions reaching almost quantitative conversion (entries $1,2,7,9$ ) the time is that for the disappearance of starting compound 1A, checked by TLC on silica gel, eluent dichloromethane. ${ }^{c}$ Yields \% of bis(2-heteroaryl) ketone, by weight; remaining percent includes mainly starting material 1A (or 1C). ${ }^{\mathrm{d}}$ DABCO: 1,4-diazabicyclo[2.2.2] cctane $^{\mathrm{e}}$ TEMPO: 2,2,6,6-tetramethyl-1piperidinyloxy, free radical. ${ }^{\mathrm{f}}$ bis(2-benzooxazolyl)methane (2C). ${ }^{\mathrm{g}}$ Bis(2-pyridyl)methane (1F). 
As previously described, ${ }^{10}$ the oxidation reaction of $\mathbf{1 A}$ with the usual oxidizing reagents $\left(\mathrm{KMnO}_{4} / \mathrm{H}_{2} \mathrm{SO}_{4}\right.$, or $\left.\mathrm{Cr}_{2} \mathrm{O}_{6} / \mathrm{H}_{2} \mathrm{SO}_{4}\right)$ produces complicated reaction mixtures from which the coupling products 4 and 5 were isolated.

Reaction between $\mathbf{1 A}$ and $\mathrm{N}$-bromosuccinimide (in equimolar amount), produces compound 5 in low yields, together with $50 \%$ of bromo bis(2-benzothiazolyl)methane (6).

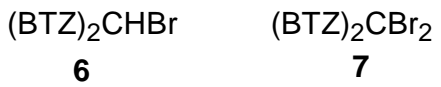

In the presence of an excess of $N$-bromosuccinimide, the dibromo derivative 7 is the major product (see experimental).

No formation of 3A was observed for reactions of 1A carried out in the absence of air or in the presence of radical inhibitors, such as 2,2,6,6-tetramethyl-1-piperidinyloxy radical (TEMPO) or thiophenol.

These facts, probably, indicate that the reaction follows a multi-step pathway with an important step involving formation of a radical species. Kinetic runs, carried out by following the appearance of 3A from 1A, were poorly reproducible and showed a curvilinear plot of $\log [\mathbf{3 A}]$ against time. We tried to obtain EPR evidence for the presence of a radical species. The only signals recorded were those related to the radical species arising from the interaction between the amine $\left(\mathrm{Et}_{3} \mathrm{~N}\right)$ and small amounts of the ketone $\mathbf{3 A}$, as tested by independent spectrum of $\mathbf{3 A}$ and the amine.

A possible intermediate of the reaction from 1A to $\mathbf{3 A}$ may be the carbinol 2A. The formation of $\mathbf{2 A}$ as an intermediate, is justified by the fact that the oxidation reaction (under the same experimental conditions of 1A) of bis(2-benzothiazolyl)ethane (8) produces the carbinol 9 (see Scheme 3).

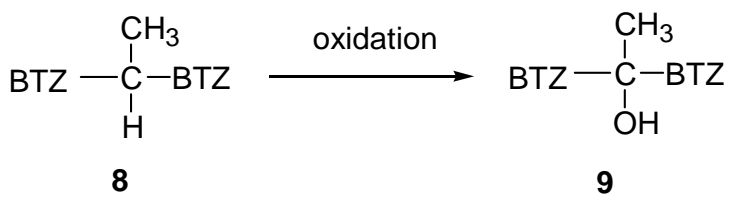

\section{Scheme 3}

We were not able to obtain evidence for the presence of $\mathbf{2 A}$ in the reaction mixtures of $\mathbf{1 A}$, (by TLC analysis and by performing runs directly in the probe of the NMR spectrometer).

\section{Oxidation of bis(heteroaryl)carbinols (2) to bis(heteroaryl)ketones (3)}

Different procedures were tried to obtain pure carbinols $\mathbf{2 A - C}$, because ketones $\mathbf{3}$ were often present in the reaction mixtures. The best way to obtain these compounds involves the reduction of the ketones 3A-C by sodium borohydride, as reported in the experimental section.

The spontaneous oxidation of $\mathbf{2 A}$ to ketone $\mathbf{3 A}$, in DMSO, THF, $\mathrm{CCl}_{4}$, is faster than that of $\mathbf{1 A}$, and the ketone $\mathbf{3 A}$ is obtained in almost quantitative yield. Infact, in the reported solvents, 2A is unstable under ambient conditions, and must be stored as a solid at $-25^{\circ} \mathrm{C}$. The low 
stability of carbinols 2 (they convert into ketones 3) necessitates their quick work up. The presence of DMSO is not essential for ketone formation from the carbinol. The key results are presented in Table 2. The behaviour in $\mathrm{CCl}_{4}$ parallels that in THF. In this case too, addition of water $(0.2 \mathrm{mmol}$, under the experimental conditions of entries 1 and 4 of Table 2) produces a small decrease in the reaction times.

In the reaction mixture of $2 \mathrm{~A}$ we did not observe the presence of $\mathbf{1 A}$. Compound $\mathbf{1 A}$ may be the second product (and it is oxidised to $\mathbf{3 A}$ at a lower rate than that of $\mathbf{2 A}$ ) if a 'dismutationlike' process takes place. The oxidation reaction of carbinols $2 \mathbf{A}, \mathbf{2 B}$ and $\mathbf{2 C}$ show a regular kinetic feature. These reactions are catalysed by bases (DABCO and $\left.\mathrm{Et}_{3} \mathrm{~N}\right)$. At $[\mathrm{DABCO}]_{\mathrm{o}}=4.9$ x $10^{-2} \mathrm{~mol} \mathrm{dm}^{-3}$, in THF, the $k_{\mathrm{obs}}$ value is not affected by the $[2 \mathbf{A}]_{\mathrm{o}}$ values $\left([2]_{\mathrm{o}}\right.$ means the initial concentration values of 2$)$ in the range $3 \times 10^{-5}$ to $4 \times 10^{-4} \mathrm{~mol} \mathrm{dm}^{-3}\left(k_{\mathrm{obs}}=6.5 \pm 0.2\right) \times 10^{-3} \mathrm{~s}^{-1}$, error is standard deviation).

Table 2. Oxidation reaction of bis(2-benzothiazolyl)carbinol (2A) [0.1 mmol in $2 \mathrm{~mL}$ of solvent] to bis(2-benzothiazolyl)ketone (3A)

\begin{tabular}{|c|c|c|c|c|}
\hline Entry & Solvent & $\begin{array}{c}\text { Base }^{\mathrm{a}} \\
\text { (experimental conditions) }\end{array}$ & Reaction time $^{\mathrm{b}}(\mathrm{h})$ & Yield \\
\hline 1 & DMSO & -- & 0.5 & $100^{\mathrm{c}}$ \\
\hline 2 & DMSO & --- & 0.5 & $98^{\mathrm{c}}$ \\
\hline 3 & DMSO & $\mathrm{Et}_{3} \mathrm{~N}$ & $\leq 0.5$ & $100^{\mathrm{c}}$ \\
\hline 4 & DMSO & $\mathrm{DABCO}^{\mathrm{d}}$ & $\leq 0.5$ & $98^{\mathrm{c}}$ \\
\hline 5 & DMSO & $\mathrm{Et}_{3} \mathrm{~N}$ (in the dark) & $\leq 0.5$ & $95^{\mathrm{c}}$ \\
\hline 6 & THF & --- & 5 & $96(98)^{\mathrm{e}}$ \\
\hline 7 & THF & $\mathrm{Et}_{3} \mathrm{~N}$ & 0.5 & $100(100)^{\mathrm{e}}$ \\
\hline 8 & THF & $--\left(\mathrm{N}_{2}\right)$ & 5 & $97(96)^{\mathrm{e}}$ \\
\hline 9 & THF & $--\left(\mathrm{N}_{2}\right.$, in the dark $)$ & 5 & $96^{\mathrm{e}}$ \\
\hline 10 & THF & $\mathrm{Et}_{3} \mathrm{~N}\left(\mathrm{TEMPO}^{\mathrm{f}}\right)$ & 0.5 & $98^{\mathrm{e}}$ \\
\hline 11 & $\mathrm{DMSO}^{\mathrm{g}}$ & --- & $33^{\mathrm{h}}$ & $4^{i}$ \\
\hline 12 & $\mathrm{DMSO}^{\mathrm{g}}$ & DABCO (air) & $33^{\mathrm{h}}$ & $37^{\mathrm{i}}$ \\
\hline
\end{tabular}

${ }^{\mathrm{a}}[$ base $]=0.1 \mathrm{mmol}$ initially added, under aerobic conditions, unless otherwise indicated. ${ }^{\mathrm{b}}$ Time (hours) for disappearance of bis(2-benzothiazolyl)carbinol (2A) checked by TLC on silica gel, eluent dichloromethane/methanol: 98/2. ${ }^{\mathrm{c}}$ Yields \% of bis(2-benzothiazolyl)ketone, by weight. ${ }^{\mathrm{d}}$ DABCO: 1,4-diazabicyclo[2.2.2] octane. $^{\mathrm{e}}$ By spectrophothometric analysis. ${ }^{\mathrm{f}}$ TEMPO: 2,2,6,6tetramethyl-1piperidinyloxy radical. The same results are obtained by adding 1,1-diphenylethene or thiophenol. ${ }^{\mathrm{g}}$ bis( $\mathrm{N}$-methyl-2-benzoimidazolyl)carbinol (2E). ${ }^{\mathrm{h}}$ Days ${ }^{\mathrm{i}}$ The remaining percent mainly includes starting carbinol (2E), checked by ${ }^{1} \mathrm{H}$ NMR analysis. 


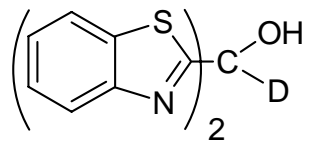

10

The oxidation of 2A to 3A follows a first order law in the carbinol until high percent of conversion $(80 \%)$ after which the reaction rate is decreased. The kinetic data obtained by initial $(50 \%)$ conversion are reported in Table 3.

Table 3. Effect of the added bases on the rate of the reaction of bis(2-heteroaryl)carbinols to ketones, at $25^{\circ} \mathrm{C}$

\section{Bis(2-benzothiazolyl)methanol (2A)}

Solvent THF

[DABCO] $\left(\mathrm{mol} \mathrm{dm}^{-3}\right) \times 10^{2}$

$k_{\mathrm{obs}}\left(\mathrm{s}^{-1}\right) \times 10^{3}$

$0.164 \quad 0.372$

0.610

0.863

1.27

1.87

2.29

Solvent DMSO

[DABCO] $\left(\mathrm{mol} \mathrm{dm}^{-3}\right) \times 10^{2}$

$k_{\text {obs }}\left(\mathrm{s}^{-1}\right) \times 10^{3}$

2.58

5.67

7.30

8.40

$11.8 \quad 15.0$

Solvent THF

$\left[\mathrm{Et}_{3} \mathrm{~N}\right]\left(\mathrm{mol} \mathrm{dm}^{-3}\right) \times 10$

$\begin{array}{llllll}---- & 0.239 & 0.910 & 1.14 & 1.57 & 2.30 \\ 0.046 & 6.37 & 23.6 & 25.3 & 38.0 & 50.7\end{array}$

$k_{\text {obs }}\left(\mathrm{s}^{-1}\right) \times 10^{2}$

$\begin{array}{lll}0.310 & 0.560 & 0.900\end{array}$

1.23

1.48

1.82

2.09

Solvent $\mathrm{THF}^{\mathrm{a}}$

$0.470 \quad 0.663$

0.833

0.953

$\begin{array}{lll}1.17 & 1.22 & 1.46\end{array}$

[DABCO] $\left(\mathrm{mol} \mathrm{dm}^{-3}\right) \times 10^{2}$

$\begin{array}{lllll}0.193 & 0.669 & 0.858 & 1.29 & 2.33\end{array}$

$k_{\mathrm{obs}}\left(\mathrm{s}^{-1}\right) \times 10^{3}$

$1.00 \quad 2.55$

3.02

$4.03 \quad 6.61$

\section{Bis(2-thiazolyl)methanol (2B)}

\section{Solvent THF}

[DABCO] $\left(\mathrm{mol} \mathrm{dm}^{-3}\right) \times 10^{2}$

0.359

1.15

1.16

1.33

2.09

2.83

$k_{\text {obs }}\left(\mathrm{s}^{-1}\right) \times 10^{6}$

3.64

4.91

5.20

5.43

7.33

8.17

Solvent DMSO

[DABCO] $\left(\mathrm{mol} \mathrm{dm}^{-3}\right) \times 10^{2}$

0.286

0.74

1.09

1.71

2.06

$k_{\text {obs }}\left(\mathrm{s}^{-1}\right) \times 10^{5}$

$0.654 \quad 1.07$

1.27

$1.65 \quad 1.81$

\section{Bis(2-benzoxazolyl)methanol (2C)}

\section{Solvent THF}

[DABCO] $\left(\mathrm{mol} \mathrm{dm}^{-3}\right) \times 10^{2}$

$\begin{array}{lll}0.730 & 1.47 & 3.36\end{array}$

5.07

5.40

10.2

$k_{\mathrm{obs}}\left(\mathrm{s}^{-1}\right) \times 10^{5}$

$\begin{array}{lll}0.805 & 0.805 & 3.90\end{array}$

4.80

5.66

12.2

a 1-Deutero bis(2-benzothiazolyl)carbinol (10). 
The decreased rate probably results from the interactions between the ketone formed during the reaction, and the starting alcohol by an equilibrium that produces an hemi-ketal, this depresses the presence of free alcohol as the ketone concentration becomes high.

Kinetic data are reported in Table 3. $k_{\mathrm{obs}}$ Values $\left(\right.$ in s$^{-1}$ ) linearly increase with increasing the value of [base].

Table 4 summarises data dissection using equation (1)

$$
k_{\mathrm{obs}}=k_{\mathrm{o}}+k_{\mathrm{B}} \mathrm{x}[\mathrm{base}]_{\mathrm{o}}
$$

where $k_{\mathrm{o}}\left(\mathrm{s}^{-1}\right)$ is the oxidation rate in the absence of base and $k_{\mathrm{B}}$ is the rate of the catalysed process in $\mathrm{s}^{-1} \mathrm{~mol}^{-1} \mathrm{dm}^{3}$.

In some cases, intercept values $\left(k_{\mathrm{o}}\right)$ show strong uncertainty, and, practically, tend to zero. The same Table 4 reports data concerning the oxidation rate of the deutero carbinol 10.

In some cases, the intersection of the straight line of equation 1 agrees well with $k_{\text {obs }}$ values independently obtained in the absence of base. The importance of base catalysis with respect to the uncatalysed oxidation is expressed by the $k_{\mathrm{B}} / k_{\mathrm{o}}$ ratios reported in Table 4 .

Table 4. Rates of transformation of bis(heteroaryl)carbinols to ketones for spontaneous process $\left(k_{0}, \mathrm{~s}^{-1}\right)$ and base catalysed process $k_{\mathrm{B}}\left(\mathrm{s}^{-1} \mathrm{~mol}^{-1} \mathrm{dm}^{3}\right)$, at $25^{\circ} \mathrm{C}$

\begin{tabular}{llllllll}
\hline Substrate & Solvent & Base $^{\mathrm{a}}$ & $k_{\mathrm{o}}{ }^{\mathrm{b}}$ & $k_{\mathrm{B}}{ }^{\mathrm{b}}$ & $k_{\mathrm{B}} / k_{\mathrm{o}}$ & $\mathrm{n}^{\mathrm{c}}$ & $\mathrm{R}^{\mathrm{d}}$ \\
\hline 2A & THF & DABCO & $(2.2 \pm 0.3) \times 10^{-3}$ & $0.54 \pm 0.03$ & 245 & 7 & 0.994 \\
2A & DMSO & DABCO & $(1.2 \pm 1) \times 10^{-3}$ & $2.2 \pm 0.1$ & 1800 & 6 & 0.996 \\
2A & THF & Et $_{3} \mathrm{~N}$ & $(3.4 \pm 0.4) 10^{-3}$ & $(5.2 \pm 0.3) \times 10^{-2}$ & 15 & 7 & 0.991 \\
2A & THF & DABCO & $(7.0 \pm 0.01) \times 10^{-4}$ & $0.26 \pm 0.01$ & 370 & 5 & 0.998 \\
2B & THF & DABCO & $(2.9 \pm 0.2) \times 10^{-6}$ & $(1.9 \pm 0.1) 10^{-4}$ & 95 & 6 & 0.990 \\
2B & DMSO & DABCO & $(5.4 \pm 0.6) \times 10^{-6}$ & $(6.4 \pm 0.4) \times 10^{-4}$ & 119 & 5 & 0.993 \\
2C & THF & DABCO & $(-6.4 \pm 4) \times 10^{-6}$ & $(1.2 \pm 0.08) \times 10^{-3}$ & --- & 6 & 0.990 \\
\hline
\end{tabular}

${ }^{a}$ DABCO: 1,4-diazabicyclo[2.2.2] octane. ${ }^{b}$ Errors are standard deviations. ${ }^{c}$ Number of points. ${ }^{d}$ Correlation coefficient. ${ }^{\mathrm{e}} 1$-Deutero bis(2-benzothiazolyl)carbinol (10).

\section{Discussion}

Oxidation of bis(heteroaryl)methanes (1) to bis(heteroaryl)ketones (3)

The oxidation reaction from $\mathrm{CH}_{2}$ to $\mathrm{CO}$ group most likely occurs in several steps, involving carbinol species 2, but we were not able to obtain evidence for the presence of carbinols 2 in the reaction mixtures from $\mathbf{1 A}$ to $\mathbf{3 A}$ (including reactions performed directly in the NMR probe). The failure to detect the presence of carbinol $\mathbf{2 A}$ is a consequence of the fact that the ketone is 
obtained by a reaction about $10^{3}$ times faster from $2 \mathbf{A}$ than the reaction from $\mathbf{1 A}$ and therefore 2A does not accumulate under the experimental conditions.

The oxidation of methane derivatives 1 requires the presence of atmospheric oxygen in the solvents (DMSO, THF, $\mathrm{CCl}_{4}$ ) used. The presence of a radical scavenger did not allow the formation of ketones (entries 6,11 of Table 1). Clearly, there is an important step involving the formation of a radical species along the oxidation reaction pathway.

We did not observe any difference between the reaction carried out in the dark and those without protection from light. In the literature ${ }^{1}$ there are attempts to explain similar oxidation reactions of the $\mathrm{C}-\mathrm{H}$ group of substituted methane derivatives to corresponding oxygenated derivatives.

Oxidation of triaryl-methanes (and of 1,1-diphenyl-ethane) in DMSO/t-butyl alcohol mixtures was studied in the presence of potassium t-butoxide. ${ }^{13}$ This reaction produces mainly carbinols by a radical mechanism (via peroxide derivatives) on the carbanion related to the starting methane (or ethane) derivatives.

A reasonable pathway for these reactions may be a photo-oxidation mechanism, but our evidence does not support this hypothesis.

Another possible reaction pathway involves the anionic species of $\mathbf{1}$, such as compound $\mathbf{1 1}$ in Scheme 4. 11 may be important in explaining the oxidation reaction in the presence of metals.

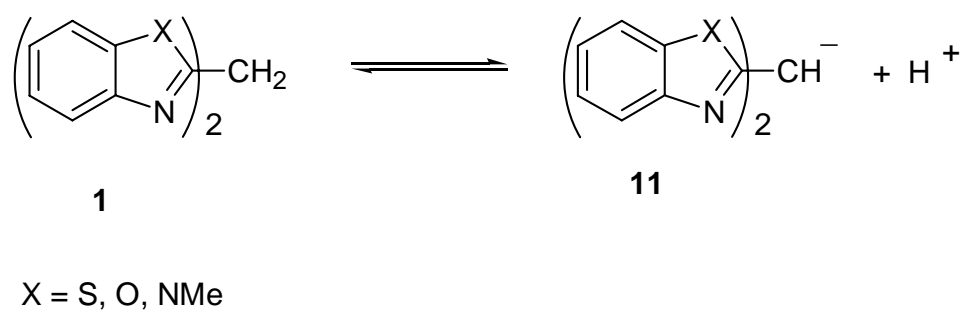

\section{Scheme 4}

Present data are hardly explained by considering the equilibrium of Scheme 4 to be important in the oxidation pathway, because the heterocyclic derivatives $\mathbf{1 C}$ and $\mathbf{1 F}$ show a reactivity significantly lower than that of $\mathbf{1 A}$, but the electron-withdrawing powers of the heterocyclic moiety are very similar, as shown by heterocyclic $\sigma$ values of the Hammett-like treatment (benzothiazole-2-yl $\sigma^{-}=0.65,{ }^{14}$ benzoxazole-2-yl $\sigma^{-}=0.68,{ }^{14}$ thiazole-2-yl, $\sigma^{-}=0.63,{ }^{15}$ pyridine-2-yl $\sigma^{-}=1.0^{14}$ ).

The addition of water to the tautomeric form of $\mathbf{1 A}$, may be an alternative for the formation of the carbinol (to the addition of oxygen), probably involving radical species. 


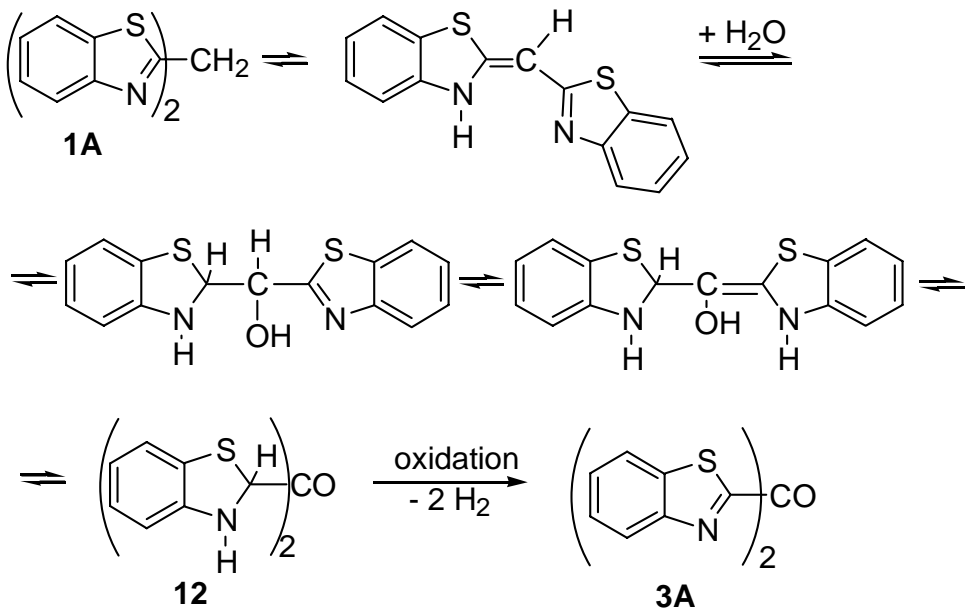

\section{Scheme 5}

The inverse addition of water to the double bond should result in a ring opening reaction or return back to $\mathbf{1 A}$.

The last step is an oxidative dehydrogenation: the aromatisation of $\mathbf{1 2}$ to $\mathbf{3 A}$ should be a simple elimination of hydrogen. All attempts to have evidence of formation of $\mathrm{H}_{2}$ failed.

Even if the data in Table 1 are qualitative, reaction pathway depicted in Scheme 5 (related to the benzothiazole derivative) is a reasonable picture to explain all the reported data. In particular the base is a catalyst to shift the tautomeric equilibrium ${ }^{16}$ depicted in Scheme 5. The first, produces the tautomer of $\mathbf{1 A}$ which is the species that reacts with water; the second produces the enol preceding the ketone 12.

The last step of Scheme 5 is an oxidative dehydrogenation: 2-benzothiazoline ${ }^{17}$ and 2thiazoline ${ }^{18}$ are indicated to be reducing agents in mildly experimental conditions.

Under the same experimental conditions reported here, the diphenylmethane is completely unreactive. This reaction pathway agrees with the fact that when the 1,1-bis(2benzothiazolyl)ethane (8) is prepared, the corresponding carbinol was recovered from the reaction mixtures.<smiles>C/C(=C1/Sc2ccccc2N1/C=C/c1ccc2nc(C(C)c3nc4ccccc4s3)sc2c1)c1nc2ccccc2s1</smiles><smiles>Cc1ccc2c(c1)SC(C(C)(O)c1nc3ccc(-c4ccc5nc(C(C)(O)c6nc7ccccc7s6)sc5c4)cc3s1)N2</smiles>

\section{Scheme 6}


The pathway reported in Scheme 5, as well as that of Scheme 6, is an alternative mechanism to the usual mechanism involving anionic/radical specie. ${ }^{19}$

Photo-oxygenation of methanes bonding isoquinoline derivatives (similar to that reported here) are indicated to start from the NH tautomer of the heterocyclic moiety. ${ }^{20}$

\section{Oxidation of bis(heteroaryl)carbinols (2) to bis(heteroaryl)ketones (3)}

Our evidence supports the idea that the oxidation of carbinols 2 to ketones 3 occurs without intervention of some radical species in the rate limiting step. The presence of a radical scavenger (entry 10 of Table 2) did not affect the yields and the reaction times. Reactions carried out in dark or in sunlight, gave the same results.

With regard to changes in the heterocyclic moiety, the oxidation of 2 parallels the behaviour observed for the oxidation of the $\mathrm{CH}_{2}$ group of compounds $\mathbf{1}$. The reactivity order is $\mathbf{2 A}>\mathbf{2 B}>$ 2C $>2$ E, 2F $>2$ D. Also in this case the electron-withdrawing power of the heterocyclic moiety appears to be unimportant. This conclusion arises not only from data presented in Table 2, but also from kinetic data in Table 4.

The rate of both oxidation reactions of compounds $\mathbf{1}$ and $\mathbf{2}$ are enhanced by the presence of a base. This fact agrees with a proton departure in a rate limiting step (equilibrium). A possible equilibrium is represented in Scheme 7.

As expected, $k_{\mathrm{o}}$ values are scarcely affected by the change in the amine used as catalyst, while $k_{\mathrm{B}}$ values (slopes of plots of $k_{\mathrm{obs}}$ versus [amine] values) depend on the amine used: the more basic $\mathrm{DABCO}$ is 10 times more efficient than $\mathrm{Et}_{3} \mathrm{~N}$.

The $k_{0}$ is poorly affected by the change of the base used [ $k_{0(\mathrm{THF})} \geq k_{0}$ (DMSO)], as required by the intramolecular hydrogen shift from carbon to the nitrogen atom. The $k_{\mathrm{B}}$ depends moderately on the solvent used: for DABCO, $k_{\mathrm{B}(\mathrm{DMSO})} / k_{\mathrm{B}(\mathrm{THF})}=4$.

Both catalysed and uncatalysed processes show a relevant isotopic effect: $k^{\mathrm{H}}{ }_{o} / k^{\mathrm{D}}{ }_{0}=3.1$ and $k^{\mathrm{H}}{ }_{\mathrm{B}} / k^{\mathrm{D}}{ }_{\mathrm{B}}=2.1$. Clearly, the $\mathrm{C}-\mathrm{H}$ bond breaking occurs in a rate limiting step for both processes. Base catalysis and isotopic effect agrees well with a reaction pathway involving the formation of the carbanionic species 13, as depicted in Scheme 7

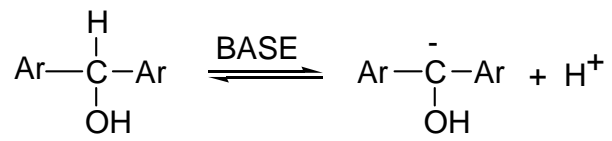

13

\section{Scheme 7}

In the case of the equilibrium depicted in Scheme 4, formation of $\mathbf{1 1}$ is a reasonable process. On the contrary, equilibrium of Scheme 7 affording the presence of the anionic specie 13, should compete with the equilibrium of formation of anion 14 from the dissociation of the $\mathrm{O}-\mathrm{H}$ group, reasonably more acid than the $\mathrm{C}-\mathrm{H}$ group. 


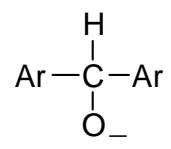

14

As a consequence in the oxidation of carbinols, the pathway involving carbanions like 13, is less likely and base catalysis on the proton departure from the $\mathrm{C}-\mathrm{H}$ group cannot be considered in the reaction pathway. Probably, the presence of $\mathbf{1 4}$ is not relevant, and, in any case it may represent a cul-de-sac. In fact, the relevant importance of a pre-equilibrium affording 14, should remove carbinols 2 from the oxidation reaction, and, consequently, the overall reaction rate should be reduced by the addition of base.

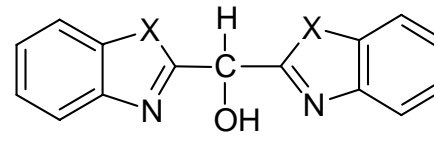

2

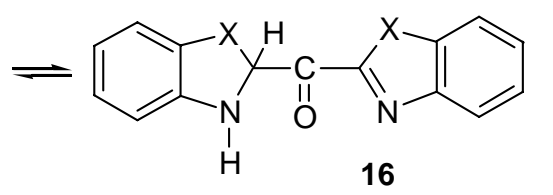

$\mathrm{X}=\mathrm{S}, \mathrm{O}$

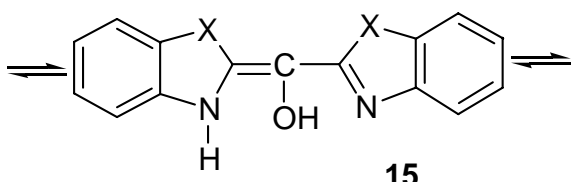

15<smiles>[R]C(=O)Nc1ccccc1[X]</smiles>

3

\section{Scheme 8}

A possible reaction pathway parallel to that of Scheme 5, is depicted in Scheme 8. In this scheme, tautomerism of $\mathbf{2}$ is an important step to obtain the ketone 16, via enol form 15. This statement agrees well with the fact that diphenylmethane is not reactive. In addition, six membered heterocyclic derivatives, such as pyridine derivatives, are less prone to afford $\mathrm{N}-\mathrm{H}$ tautomers compared to five membered heterocycles. ${ }^{21}$ Thus, the oxidation of pyridine derivatives is significantly slower than the oxidation of thiazole and benzothiazole derivatives. Regarding five membered ring systems, benzothiazole derivatives are more prone to give 'non-aromatic' tautomeric form than the thiazole derivatives: the oxidation of benzothiazole derivatives is faster than that of thiazole derivatives. From 16, ketones $\mathbf{3}$ are easily obtained by oxidative dehydrogenation. ${ }^{18}$

\section{Conclusions}

In conclusion, the oxidation of bis(heteroaryl)methanes occurs by a radical oxidation involving the NH tautomer of $\mathbf{1}$. The oxidation reactions of carbinols $\mathbf{2}$ occur via two tautomeric equilibria, 
which are favored by the presence of base. In both reactions, the partially saturated compounds $\mathbf{1 2}$ and $\mathbf{1 6}$ are formed in the final step which, probably, is a fast step.

\section{Experimental Section}

General Procedures. ${ }^{1} \mathrm{H}$ and ${ }^{13} \mathrm{C}$ NMR spectra were recorded on a Varian Gemini spectrometer at 300 and $75.46 \mathrm{MHz}$, respectively. Chemical shifts are referenced to solvent. $J$ values are given in Hz. Mass spectra were recorded at an ionisation voltage of $70 \mathrm{eV}$ on a VG $7070 \mathrm{E}$ spectrometer. Thin-layer chromatography was performed on Merck Kieselgel $60 \mathrm{~F}_{254}$. Melting points were measured with a Büchi apparatus and are uncorrected. THF was distilled from sodium benzophenone ketyl. Air and moisture sensitive solutions and reagents were handled in dried apparatus under an atmosphere of dry nitrogen.

Uv/vis spectrophotometric data were recorded with a Perkin Elmer (model Lambda 12) spectrophotometer. Under the reported experimental conditions, uv/vis spectrophotometric analysis (as well as the TLC analysis) did not show evidence for the presence of other oxidation/condensation products other than keto derivatives 3.

Kinetic measurements were performed by the usual procedures, by following the appearance of compounds 3, until high percent of conversion, at $\lambda_{\max }$ values here reported: $\mathbf{3 A} \lambda_{\max }=343 \mathrm{~nm}(\varepsilon$ $\left.=2.05 \times 10^{5}\right) ; 3 \mathbf{B} \lambda_{\max }=325 \mathrm{~nm}\left(\varepsilon=2.20 \times 10^{3}\right) ; 3 \mathbf{C} \lambda_{\max }=335 \mathrm{~nm}\left(\varepsilon=1.82 \times 10^{5}\right)$

Table 3 reports $\mathrm{k}_{\mathrm{obs}}$ values $\left(\mathrm{s}^{-1}\right)$.

\section{Products}

Compounds 1D, 2D, 1F and 3F are commercially available.

Preparation of 1,1-bis(heteroaryl)methanes 1. 1,1-Bis(2-benzothiazolyl)methane (1A). Compound 1A was prepared by adding polyphosphoric acid $(63 \mathrm{~mL})$ to a mixture of 2aminothiophenol $(90 \mathrm{mmol})$ and malononitrile $(45 \mathrm{mmol})$, heated at $150^{\circ} \mathrm{C}$ with vigorous mechanical stirring and kept at this temperature for $2 \mathrm{~h}$. The reaction mixture was poured in a ice/water mixture, neutralised by addition of $\mathrm{KOH}$ followed by $\mathrm{NaHCO}_{3}$. The yellow precipitate was filtered, washed with water, dried in a desiccator in vacuo over $\mathrm{P}_{2} \mathrm{O}_{5}$, then chromatographed on silica gel column (eluant: $\mathrm{CH}_{2} \mathrm{Cl}_{2} / \mathrm{CH}_{3} \mathrm{OH}$ 99/1). Compound $\mathbf{1 A}$ was obtained in $80 \%$ yield. M.p.: $95-96{ }^{\circ} \mathrm{C}$ (Lit., ${ }^{22}$ 95-95.5 ${ }^{\circ} \mathrm{C}$ ). Chemico-physical data for compound $\mathbf{1 A}$ are in agreement with those reported. ${ }^{8 \mathrm{a}, 9}$

1,1-Bis(2-benzooxazolyl)methane (1C). Compound 1C was obtained in 25\% yield from 2aminophenol and malononitrile in a similar procedure to obtain 1A. mp $119-120^{\circ} \mathrm{C}$ (Lit., ${ }^{23}$ $\left.116^{\circ} \mathrm{C}\right) . \quad \delta_{\mathrm{H}}\left(300 \mathrm{MHz}, \mathrm{CDCl}_{3}\right) 4.67(2 \mathrm{H}, \mathrm{s}, \mathrm{H}-8), 7.33-7.38(2 \mathrm{H}, \mathrm{m}, \mathrm{H}-6), 7.51-7.55$ (2H, m, H5), 7.72-7.74 (2H, m, H-7), 7.74-7.76 (2H, m, H-4); $\delta_{\mathrm{C}}\left(75.56 \mathrm{MHz}, \mathrm{CDCl}_{3}\right)$ 29.3, 110.7, 120.2, 124.5, 125.3, 141.1, 151.1, 159.7; MS (EI) m/z: $250\left(\mathrm{M}^{+}\right), 221,132$. 
1,1-Bis(2-benzothiazolyl)ethane (8). Compound 8 was prepared by a condensation reaction of 2-aminothiophenol and diethyl methylmalonate in polyphosphoric acid at $250^{\circ} \mathrm{C}$ following the procedure described for the synthesis of 1A. The reaction mixture contains small amount (about $10 \%$ ) of starting materials, and compounds 8 and 9 in the relative ratio $2: 1$ (calculated by ${ }^{1} \mathrm{H}$ NMR analysis). Compound 8 was separated from the solution in dichloromethane, by dropwise addition of ethanol. Separated white crystals (mp 170-172 ${ }^{\circ} \mathrm{C}$, Lit., ${ }^{9} 165^{\circ} \mathrm{C}$ ) show chemicophysical data in agreement with literature data, ${ }^{9}$ which states the predominance of tautomeric form 8bis in describing 8. MS (EI) m/z: $296\left(\mathrm{M}^{+}\right)$, 281, 297, 162, 148, 135.

Attempts to perform mono alkylation of $\mathbf{1 A}$ in THF (by metalation with butyllithium at $-70{ }^{\circ} \mathrm{C}$ under nitrogen atmosphere followed by quenching with iodomethane) afforded 2,2-bis(2benzothiazolyl)-2,2-propane ${ }^{8 \mathrm{a}}(\mathbf{1 5})\left(\mathrm{mp} 128-129{ }^{\circ} \mathrm{C}\right.$, Lit., $\left.{ }^{8 \mathrm{a}} 132-134{ }^{\circ} \mathrm{C}\right)$ and small amount of carbinol 9 (10\% of yield).
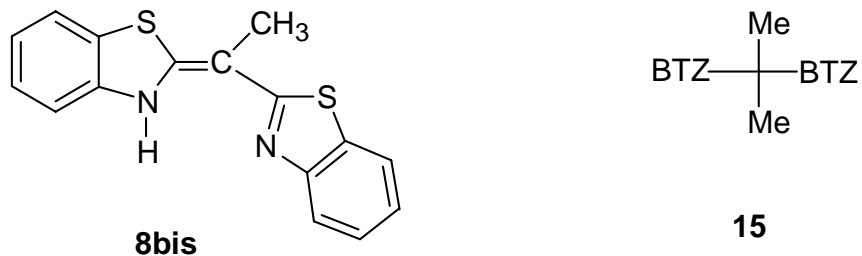

Preparation of ketones 3. Bis(2-benzothiazolyl) ketone (3A). Oxidation reaction of $1 \mathrm{~A}(1.5 \mathrm{~g}$, $5.3 \mathrm{mmol})$ with $\mathrm{H}_{2} \mathrm{O}_{2}(49.4 \mathrm{mmol})$ in $\mathrm{CH}_{3} \mathrm{COOH}(18 \mathrm{~mL})$ afforded, after $24 \mathrm{~h}$. at room temperature, spontaneous precipitation of $3 \mathrm{~A}$ (yield $=60 \%$ ) which was filtered, washed with water, dried in a desiccator and purified by chromatographic column (silica gel, eluent $\mathrm{CH}_{2} \mathrm{Cl}_{2}$ ). mp $182-183^{\circ} \mathrm{C}$ (Lit., ${ }^{24} 183{ }^{\circ} \mathrm{C}$ ). Chemico-physical data of $\mathbf{3 A}$ are in agreement with those reported. ${ }^{11} \delta_{\mathrm{H}}\left(300 \mathrm{MHz}, \mathrm{CDCl}_{3}\right)$ 7.49-7.57 (2H, m, H-6), 7.59-7.67 (2H, m, H-5), 7.74-7.78 (2H, $\mathrm{m}, \mathrm{H}-7), 8.09-8.14(2 \mathrm{H}, \mathrm{m}, \mathrm{H}-4) ; \delta_{\mathrm{C}}\left(75.56 \mathrm{MHz}, \mathrm{CDCl}_{3}\right) 122.1,126.2,127.3,128.3,137.8$, $153.2,162.1,176.4$.

Bis(2-thiazolyl) ketone (3B). A solution of thiazole $(0.26 \mathrm{~mL}, 5.0 \mathrm{mmol})$ in $5.0 \mathrm{~mL}$ of anhydrous THF was treated with $n$-butyllithium $\left(5.5 \mathrm{mmol}, 1.5 \mathrm{M}\right.$ in $n$-hexane), at $-70^{\circ} \mathrm{C}$. After $30 \mathrm{~min}$, a solution of diethyl carbonate $(2.5 \mathrm{mmol}$ in $5 \mathrm{~mL}$ of THF) was added. After $1 \mathrm{~h}$, the reaction mixture was treated with $5 \mathrm{~mL}$ of saturated aqueous solution of $\mathrm{NH}_{4} \mathrm{Cl}$ and extracted with diethyl ether. The organic layers were dried over anhydrous sodium sulfate, filtered and concentrated in vacuo. Compound 3B was obtained in $65 \%$ yield after purification by flash chromatography (eluent: petroleum light/ diethyl ether 4:6). mp 139-141 ${ }^{\circ} \mathrm{C}$ (Lit., ${ }^{25} 141-142{ }^{\circ} \mathrm{C}$ ). Spectral data of 3B are in agreement with those reported. ${ }^{26}$

Bis(2-benzooxazolyl) ketone (3C). 3-Chloroperbenzoic acid (4.56 mmol) was added, portionwise, at $0^{\circ} \mathrm{C}$, to a solution of $1 \mathrm{C}(0.800 \mathrm{~g}, 3.90 \mathrm{mmol})$ in anhydrous $\mathrm{CH}_{2} \mathrm{Cl}_{2}(5.0 \mathrm{~mL})$. After $12 \mathrm{~h}$, a yellow precipitate appeared and the TLC analysis of the solution showed the presence of the compound 3C. After filtration and concentration of the solution, the residue was purified by flash chromatography (eluent: $\mathrm{CH}_{2} \mathrm{Cl}_{2}$ ). Compound $3 \mathrm{C}$ was obtained in $60 \%$ yield. 
mp 174-176 ${ }^{\circ} \mathrm{C}$ (Lit., ${ }^{11} 173-175^{\circ} \mathrm{C} . \delta_{\mathrm{H}}\left(300 \mathrm{MHz}, \mathrm{CDCl}_{3}\right)$ 7.48-7.69 (4H, m, H-5 and H-6), 7.72$7.80(2 \mathrm{H}, \mathrm{m}, \mathrm{H}-7), 8.08-8.17(2 \mathrm{H}, \mathrm{m}, \mathrm{H}-4) ; \delta_{\mathrm{C}}\left(75.56 \mathrm{MHz}, \mathrm{CDCl}_{3}\right) 111.9,123.4,126.2,129.5$, 141.0, 150.8, 155.7, 168.1; MS (EI) m/z: $264\left(\mathrm{M}^{+}\right)$, 236, 208, 146, 119, 102, 90.

Bis(1-methylbenzoimidazol-2-yl) ketone (3E). To a solution of $N$-methylbenzimidazole $(0.88 \mathrm{~g}$, $6.66 \mathrm{mmol})$ in anhydrous diethyl ether $(24 \mathrm{~mL})$, kept at $-78^{\circ} \mathrm{C}$ in a dried flask and under nitrogen atmosphere, a solution $(2.8 \mathrm{~mL})$ of $n$-butyl lithium $(2.5 \mathrm{M}$ in $n$-hexane) was added dropwise. After stirring for $2.5 \mathrm{~h}$, a solution of $0.4 \mathrm{~mL}(3.33 \mathrm{mmol})$ of diethyl carbonate in anhydrous diethyl ether $(2.0 \mathrm{~mL})$ was added dropwise and the mixture was allowed to warm to room temperature overnight. The reaction mixture was acidified with $10 \% \mathrm{HCl}$ and stirred until the precipitate formed during the reaction was dissolved. The solution was extracted with diethyl ether $(3 \times 10 \mathrm{~mL})$ and the aqueous layer was basified with $5 \mathrm{~N} \mathrm{NH}_{4} \mathrm{OH}$. The white precipitate obtained was collected over a Gooch funnel and washed with water until the $\mathrm{pH}$ of the mother liquor was neutral. The solid was dried in a desiccator and purified by crystallization from methanol (0.58g, 60\%): mp 189-191 ${ }^{\circ} \mathrm{C}$ (Lit., $\left.{ }^{27} 190-191{ }^{\circ} \mathrm{C}\right), \delta_{\mathrm{H}}\left(300 \mathrm{MHz}, \mathrm{CDCl}_{3}\right) 4.15(6 \mathrm{H}, \mathrm{s}$, $\left.\mathrm{CH}_{3}\right), 7.30-7.52$ (6H, m, H-5, H-6 and H-7), 7.95-8.03 (2H, m, H-4), $\delta_{\mathrm{C}}\left(75.56 \mathrm{MHz}, \mathrm{CDCl}_{3}\right)$ 32.0, 110.2, 122.9, 123.7, 126.2, 136.8, 142.4, 146.8, 180.8; IR $\left(\mathrm{CHCl}_{3}\right), v\left(\mathrm{~cm}^{-1}\right): 1654$; MS (EI) m/z: $290\left(\mathrm{M}^{+}\right), 261,159,145,132$; HRMS: calc. for $\mathrm{C}_{17} \mathrm{H}_{14} \mathrm{~N}_{4} \mathrm{O}_{1}: 290.1168$, found: 290.1163 .

Synthesis of carbinols 2A-C. Preparation of bis(benzothiazol-2-yl)methanol (2A): typical procedure. A solution of sodium borohydride $(0.027 \mathrm{~g}, 0.71 \mathrm{mmol})$ in methanol $(1.0 \mathrm{~mL})$ was added, at $0{ }^{\circ} \mathrm{C}$, in a dried flask and under nitrogen, to a solution of $\mathbf{3 A}(0.198 \mathrm{~g}, 0.67 \mathrm{mmol})$ in 4.0 $\mathrm{mL}$ of dichloromethane. The addition of $\mathrm{NaBH}_{4}$ produces a colour change of the solution from yellow (typical of ketone) to dark green. If the colour reverted back to yellow, additional $\mathrm{NaBH}_{4}$ was added. When the TLC analysis (eluent: $\mathrm{CH}_{2} \mathrm{Cl}_{2}: \mathrm{CH}_{3} \mathrm{OH}$ 99:1) showed complete conversion of the starting material, the reaction mixture was treated with water and extracted with $\mathrm{CH}_{2} \mathrm{Cl}_{2}$; the organic layers were washed with brine and dried over anhydrous sodium sulfate. After concentration in vacuo, the residue was stored at $-18{ }^{\circ} \mathrm{C}$. The yield is almost quantitative if the whole working-up is carried out in $30 \mathrm{~min}$. The melting point is poorly reproducible because the carbinol is very prone to oxidation to the corresponding ketone. Carbinols may be stored in dark at $-20^{\circ} \mathrm{C}$ for several days.

Bis(benzothiazol-2-yl)methanol (2A). $\delta_{\mathrm{H}}\left(300 \mathrm{MHz}, \mathrm{CDCl}_{3}\right)$ 5.12-5.22 (1H, br s, OH), 6.56 (1H, s, H-8), 7.38-7.48 (2H, m, H-6), 7.48-7.58 (2H, m, H-5), 7.85-7.95 (2H, m, H-7), 8.10-8.25 $(2 \mathrm{H}, \mathrm{m}, \mathrm{H}-4)$, Sometimes, a coupling between $\mathrm{H}-8$ and $\mathrm{OH}(\mathrm{J}=4.1 \mathrm{~Hz})$ was observed. $\delta_{\mathrm{C}}(75.56$ $\left.\mathrm{MHz}, \mathrm{CDCl}_{3}\right)$ 72.4, 121.9, 123.3, 125.5, 126.3, 135.4, 152.4, 171.3.

All attempts to prepare 2A from the corresponding bromo derivative bis(benzothiazol-2yl)bromomethane (6) by hydrolysis reaction failed.

Bis(benzothiazol-2-yl)-1-deutero-methanol $2 \mathbf{A}\left(\mathbf{d}_{\mathbf{1}}\right)$. This compound was obtained by following the typical procedure, using sodium borodeuteride: $\delta_{\mathrm{H}}\left(300 \mathrm{MHz}, \mathrm{CDCl}_{3}\right) 5.10-5.20(1 \mathrm{H}$, br s, $\mathrm{OH}), 7.38-7.44$ (2H, m, H-6), 7.48-7.54 (2H, m, H-5), 7.87-7.90 (2H, m, H-7), 8.05-8.09 (2H, m, $\mathrm{H}-4)$. 
Bis(thiazol-2-yl)methanol (2B). $\delta_{\mathrm{H}}\left(300 \mathrm{MHz}, \mathrm{CDCl}_{3}\right)$ 5.7-6.2 (1H, br s, OH), 6.40 (2H, s, H-6), $7.36(2 \mathrm{H}, \mathrm{d}, J=3.3 \mathrm{~Hz}, \mathrm{H}-4), 7.77(2 \mathrm{H}, \mathrm{d}, J=3.3 \mathrm{~Hz}, \mathrm{H}-5)$; $\delta_{\mathrm{C}}\left(75.56 \mathrm{MHz}, \mathrm{CDCl}_{3}\right) 71.2,120.3$, $142.3,171.2$.

Bis(benzooxazol-2-yl)methanol (2C). $\delta_{\mathrm{H}}\left(300 \mathrm{MHz}, \mathrm{CDCl}_{3}\right) 4.55-4.65(1 \mathrm{H}$, br s, OH), 6.32-6.38 (1H, s, H-8), 7.36-7.38 (2H, m, H-5), 7.39-7.41 (2H, m, H-6), 7.53-7.56 (2H, m, H-4), 7.76-7.79 $(2 \mathrm{H}, \mathrm{m}, \mathrm{H}-7) ; \delta_{\mathrm{C}}\left(75.56 \mathrm{MHz}, \mathrm{CDCl}_{3}\right) 65.1,111.1,120.5,124.8,125.9,140.2,151.0,162.3$.

Synthesis of bis(1-methyl-1H-benzoimidazol-2-yl)methanol (2E). This compound was obtained as a mixture with bis (1-methylbenzimidazol-2-yl) ketone when the reaction was carried out in anhydrous THF, quenched, after $30 \mathrm{~min}$., with saturated aqueous $\mathrm{NH}_{4} \mathrm{Cl}$ solution and extracted with dichloromethane. After concentration of the organic layer, the F.C. of the residue (eluent: methanol) gave the carbinol (30\%): white solid, mp $238-243{ }^{\circ} \mathrm{C}$ (dec.), Lit., ${ }^{28} 232-$ $235^{\circ} \mathrm{C} ; \delta_{\mathrm{H}}\left(300 \mathrm{MHz}, \mathrm{DMSO}-\mathrm{d}_{6}\right) 4.02\left(6 \mathrm{H}, \mathrm{s} . \mathrm{CH}_{3}\right), 6.60(1 \mathrm{H}, \mathrm{d}, J=5.5 \mathrm{~Hz}, \mathrm{CHOH}), 7.02(1 \mathrm{H}$, $\mathrm{d}, J=5.5 \mathrm{~Hz}$, disappears after addition of $\left.\mathrm{D}_{2} \mathrm{O}, \mathrm{OH}\right), 7.29(2 \mathrm{H}, \mathrm{td}, J=7.9 \mathrm{~Hz}, J=1.2 \mathrm{~Hz}, \mathrm{H}-5$ or H-6), 7.38 (2H, td, $J=7.1 \mathrm{~Hz}, J=1.0 \mathrm{~Hz}, \mathrm{H}-5$ or H-6), 7.64-7.74 (4H, m, H-4 and H-7); $\delta_{\mathrm{H}}(300$ $\left.\mathrm{MHz}, \mathrm{CD}_{3} \mathrm{OD}\right) 4.83(6 \mathrm{H}, \mathrm{s}), 6.53(1 \mathrm{H}, \mathrm{s}), 7.27(2 \mathrm{H}, \mathrm{td}, J=7.4 \mathrm{~Hz}, J=1.3 \mathrm{~Hz}), 7.35(2 \mathrm{H}, \mathrm{td}, J=$ $7.1 \mathrm{~Hz}, J=1.1 \mathrm{~Hz}), 7.49-7.55(2 \mathrm{H}, \mathrm{m}), 7.61-7.67(2 \mathrm{H}, \mathrm{m}) ; \delta_{\mathrm{C}}\left(75.56 \mathrm{MHz}, \mathrm{CDCl}_{3}\right) 31.9,66.8$, 111.4, 120.4, 124.0, 124,9, 138.1, 142.8, 153.4; MS (EI) m/z: $292\left(\mathrm{M}^{+}\right), 275,263,161,146,131$.

1,1-Bis benzothiazol-2-yl-ethanol (9). Compound 9 was also prepared by the following procedure. Butyllithium $(20 \mathrm{mmol})$ was added dropwise to a solution of benzothiazole (20 $\mathrm{mmol})$ in $\mathrm{THF}(50 \mathrm{~mL})$ at $-80^{\circ} \mathrm{C}$ under nitrogen and with vigorous stirring. Acetyl chloride (10 $\mathrm{mmol}$ ) in $10 \mathrm{~mL}$ of THF was slowly added under vigorous stirring. After 8 hours the reaction mixture was poured into an ice-water mixture and extracted with $\mathrm{Et}_{2} \mathrm{O}$. From the $\mathrm{Et}_{2} \mathrm{O}$ solution, bis(2-benzothiazole) (identified by comparison with an authentic sample) spontaneously precipitates. Carbinol 9 was separated from mother solution by addition of chloroform and slow crystallisation. Yields $30 \%$. mp $154-155^{\circ} \mathrm{C}$, Lit., ${ }^{28} 154-156{ }^{\circ} \mathrm{C}$. Spectral data of compound 9 are in agreement with those reported in literature. ${ }^{28}$

\section{Reaction of 1,1-bis(2-benzothiazolyl)methane (1A) with N-bromosuccinimide (NBS).} $\mathrm{N}$-Bromosuccinimide was added, under vigorous stirring, to a solution of $\mathbf{1 A}$ in $10 \mathrm{~mL}$ of solvent, as reported in Table 5. The reaction mixture was refluxed for 4 hours, then the solvent was removed under vacuum and the residue chromatographed on silica gel column (eluent: $\mathrm{CH}_{2} \mathrm{Cl}_{2}$ ) in order to eliminate unreacted succinimide and to separate reaction products.

Table 5 reports some details on this reaction. Reaction products are indicated in scheme 9. Bromination reaction of $\mathbf{1 A}$ by molecular bromine afforded tars.

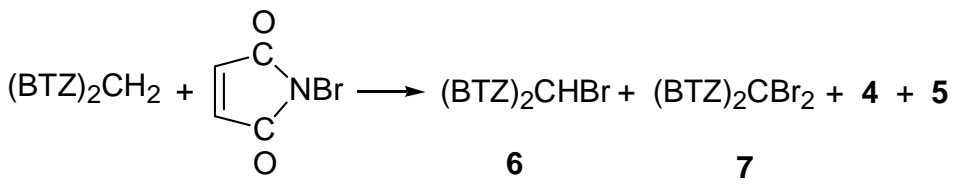

\section{Scheme 9}


Table 5. Reaction of $\mathbf{1 A}$ and $N$-bromosuccinimide (NBS)

\begin{tabular}{lllll}
\hline Molar ratio & Solvent and other & $\mathrm{T}\left({ }^{\circ} \mathrm{C}\right)$ & Reaction time $(\mathrm{h})$ & Products (yield \%) \\
\hline 1A/NBS $1: 1.2$ & $\mathrm{CH}_{3} \mathrm{OH}$ & 25 & 2 & $\mathbf{5}(70)$ \\
1A/NBS $1: 1$ & $\mathrm{CH}_{3} \mathrm{OH}$ & 25 & 2 & $\mathbf{5}(81)$ \\
1A/NBS $1: 2$ & $\mathrm{CCl}_{4}$ & 77 & 5 & $\mathbf{7}(53)$ \\
1A/NBS $1: 1$ & $\mathrm{CCl}_{4}$ and $\mathrm{AIBN}^{\mathrm{a}}$ & 77 & 5 & $\mathbf{6}(66) ; \mathbf{5}(7)$ \\
1A/NBS $1: 1$ & $\mathrm{CCl}_{4}$ & 77 & 2 & $\mathbf{6}(51)$ \\
\hline
\end{tabular}

${ }^{\mathrm{a}}$ Traces $(0.01 \mathrm{mmol})$.

Bis(benzothiazol-2-yl)bromomethane (6). $\mathrm{mp} 228-230{ }^{\circ} \mathrm{C}, \delta_{\mathrm{H}}\left(300 \mathrm{MHz}, \mathrm{CDCl}_{3}\right) 6.90(1 \mathrm{H}, \mathrm{s}$, H-8), 7.41-7.57 (4H, m, H-5 and H-6), 7.88-7.95 (2H, m, H-7), 8.05-8.13 (2H, m, H-4); $\delta_{\mathrm{C}}(75.56$ $\left.\mathrm{MHz}, \mathrm{CDCl}_{3}\right) 43.5,121.8,124.0,126.1,126.6,136.3,152.6,166.6$; $\mathrm{MS}(\mathrm{EI}) \mathrm{m} / \mathrm{z}: 362\left(\mathrm{M}^{+}+2\right)$, $360\left(\mathrm{M}^{+}\right), 282,148,135,82,80$.

Bis(benzothiazol-2-yl)dibromomethane (7). $\mathrm{mp} 124-126{ }^{\circ} \mathrm{C}, \delta_{\mathrm{H}}\left(300 \mathrm{MHz}, \mathrm{CDCl}_{3}\right)$ 7.44-7.50 (2H, m, H-6), 7.51-7.56 (2H, m, H-5), 7.87-7.90 (2H, m, H-7), 8.08-8.11 (2H, m, H-4); $\delta_{\mathrm{C}}(75.56$ $\left.\mathrm{MHz}, \mathrm{CDCl}_{3}\right)$ 51.2, 121.4, 124.4, 126.4, 126.6, 137.1, 152.4, 169.8; MS (EI) m/z: 440 (M $\left.{ }^{+}\right), 362$, $360,282,268,228,226,215,213,135,82,80$.

\section{Acknowledgements}

The authors thank the Ministero dell'Universita' e della Ricerca Scientifica e Tecnologica, and the University of Bologna (Funds for selected research topics, 2001-2003). Many thanks are due to Mr. Luca Zuppiroli for executing MS spectra.

\section{References}

1. (a) Sheldon, A. R.; Kochi, J. K. Metal-Catalyzed Oxidation of Organic Compounds, Academic Press: New York, 1981. (b) Barton, D. H. R.; Martell, A. E.; Sawyer D. T. Eds.; The Activation of Dioxygen and Homogeneous Catalytic Oxidation; Plenum Press: New York, 1993.

2. Hotz, H. D. J. Org. Chem. 1972, 37, 2069.

3. Casnyi, L. J.; Jaky, K. J. Mol. Catal. A 1997, 120, 125.

4. Katsuhisa, M.; Takahiro, I.; Satoshi, S.; Yasukada, I. Tetrahedron Lett. 1999, 40, 2165.

5. Lee-Ruff, E. Chem. Soc. Rev. 1977, 2, 195. Lee-Ruff, E.; Timms, N. Can. J. Chem. 1980, 58, 2138.

6. (a) Neumann, R.; Sasson,Y. J. Org. Chem. 1984, 49, 1282. (b) Rawson, G.; Wynberg, H. Recueil Trav. Chim. Pays-Bas 1971, 90, 39. 
7. Zubaroskii, V. M. Zh. Obshch. Khim. 1951, 21, 2199; Chem. Abs. 1952, 8098f.

8. (a) Babudri, F.; Florio, S.; Ingrosso, G. Heterocycles 1986, 24, 2215. (b) Ramos, M. T.; Avendaño, C.; Elguero, J. J. Heter. Chem. 1987, 24, 247. (c) Ramos, M. T.; Avendaño, C.; Elguero, J.; Jimeno, M. L. Bull. Soc. Chim. Belg. 1989, 98, 497.

9. Avendaño, C.; Ramos, M. T.; Elguero, J.; Jimeno, M. L.; Bellanato, J.; Florencio, F. Can. J. Chem. 1988, 66, 1467.

10. Boga, C.; Bonamartini, A. C.; Forlani, L.; Mezzina, E.; Pompa, A.; Sgarabotto, P.; Spinelli, D.; Todesco, P. E. J. Chem. Res. (S) 1999, 410, (M), 1999, 1737.

11. Abbotto, A.; Bradamante, S.; Pagani, G. A. Gazzetta Chim. It. 1994, 124, 301.

12. Leete, E.; Marion, L. Can. J. Chem. 1952, 30, 563.

13. Russel, G. A.; Bemis, A. G. J. Amer. Chem. Soc. 1966, 88, 5491.

14. Exner, O. Correlation Analysis in Chemistry, Recent Advances; Chapman, N. B.; Shorter, J., Eds.; Plenum Press: New York, 1978.

15. (a) Otsui, Y.; Kimura, T.; Sugimoto, Y.; Imoto, E.; Omori, Y.; Okawara, T. Nippon Kagaku Zhassi 1959, 80, 1024; Chem. Abstr. 1961, 55, 5467. (b) Forlani, L. Gazz. Chim. It. 1981, $111,159$.

16. Annese, M.; Forlani, L.; Bonamartini, A. C.; Rizzoli, C.; Sgarabotto, P. J. Chem. Soc. Perkin Trans. 2 1994, 615.

17. Chikashita, H.; Myazaki, M.; Itoh, K. Synthesis 1984, 308.

18. D’Auria, M.; Mauriello, G.; Racioppi, R. J. Chem. Soc., Perkin Trans. 1 1999, 37.

19. Bradamante, S.; Facchetti, A.; Pagani, G. A. Gazz. Chim. Ital. 1996, 126, 329.

20. Martin, N. H.; Jefford, C. W. Helv. Chim. Acta 1982, 65, 762.

21. (a) Forlani, L. Targets in Heterocyclic Chemistry, Attanasi, O. A.; Spinelli, D., Eds.; Italian Society of Chemistry: Roma, 1997, Vol.1, pp 75. (b) Elguero, J.; Marzin, C.; Katritzky, A. R.; Linda, P. The Tautomerism of Heterocycles; Academic Press: London, 1976.

22. Rai, C.; Braunwart, J. B. J. Org. Chem. 1961, 26, 3434.

23. Ried, W.; Patschorke, J. Liebigs Annalen der Chemie 1956, 599, 44.

24. Jutzi, P.; Gilge, U. J. Heterocycl. Chem. 1983, 1011.

25. Pedulli, G. F.; Zanirato, P.; Alberti. A.; Tiecco, M. J. Chem. Soc. Perkin Trans. 2 1975, 293.

26. Dondoni, A.; Fantin, A.; Fogagnolo, M.; Medici, A.; Pedrini, P. J. Org. Chem. 1988, 53, 1748.

27. Gorun, S. M.; Stibrany, R. T.; Katritzky, A. R.; Slawinski, J. J.; Faid-Allah, H.; Brunner, F. Inorg. Chem. 1996, 35, 3.

28. Boga, C.; Forlani, L.; Todesco, P. E. Gazz. Chim. It. 1997, 127, 197. 